\title{
Effects of Swimming Training on Blood Pressure and Vascular Function in Adults $>50$ Years of Age
}

\author{
Nantinee Nualnim, PhD, Kristin Parkhurst, MS, Mandeep Dhindsa, MA, Takashi Tarumi, MA, \\ Jackie Vavrek, MS, and Hirofumi Tanaka, PhD*
}

\begin{abstract}
Swimming is ideal for older adults because it includes minimum weight-bearing stress and decreased heat load. However, there is very little information available concerning the effects of regular swimming exercise on vascular risks. We determined if regular swimming exercise would decrease arterial blood pressure (BP) and improve vascular function. Forty-three otherwise healthy adults $>50$ years old $(60 \pm 2)$ with prehypertension or stage 1 hypertension and not on any medication were randomly assigned to 12 weeks of swimming exercise or attention time controls. Before the intervention period there were no significant differences in any of the variables between groups. Body mass, adiposity, and plasma concentrations of glucose and cholesterol did not change in either group throughout the intervention period. Casual systolic BP decreased significantly from $131 \pm 3$ to $122 \pm$ $4 \mathrm{~mm} \mathrm{Hg}$ in the swimming training group. Significant decreases in systolic BP were also observed in ambulatory (daytime) and central (carotid) BP measurements. Swimming exercise produced a $21 \%$ increase in carotid artery compliance $(\mathrm{p}<0.05)$. Flow-mediated dilation and cardiovagal baroreflex sensitivity improved after the swim training program ( $p$ <0.05). There were no significant changes in any measurements in the control group that performed gentle relaxation exercises. In conclusion, swimming exercise elicits hypotensive effects and improvements in vascular function in previously sedentary older adults. (C) 2012 Elsevier Inc. All rights reserved. (Am J Cardiol 2012;109: 1005-1010)
\end{abstract}

Regular exercise is universally the first-line approach to prevent and treat age-related increases in blood pressure (BP). ${ }^{1}$ Most studies to date, however, have employed walking, jogging, or cycling as activity modes. ${ }^{2}$ Currently, there is very little information available concerning the BP-lowering effects of regular swimming exercise. Thus far swimming exercise has been widely promoted and prescribed without the underpinning of firm scientific support from clinical studies. ${ }^{3}$ This is unfortunate because swimming is an ideal form of physical activity for older adults, particularly those with orthopedic problems, bronchospasm, heat disorders, and/or obesity, because it includes minimum weight-bearing stress, a humid environment, and decreased heat load. ${ }^{3}$ In addition, no information is available on whether regular swimming exercise modulates key measurements of vascular function (arterial stiffness and endothelium-dependent vasodilation) and whether they are related to the hypotensive effects of swimming exercise. The primary aim of the present study was to determine the effect of swimming exercise intervention on arterial BP and key measurements of vascular functions in adults $>50$ years of age with increased BP. To evaluate the effects on BP as

Cardiovascular Aging Research Laboratory, Department of Kinesiology and Health Education, The University of Texas at Austin, Austin, Texas. Manuscript received September 13, 2011; revised manuscript received and accepted November 14, 2011.

The study was supported by Grant-in-Aid 2010136 from the American Heart Association.

*Corresponding author: Tel: 512-232-4801; fax: 512-471-0946.

E-mail address: htanaka@mail.utexas.edu (H. Tanaka). comprehensively as possible, measurements of ambulatory, central, and casual BP were performed.

\section{Methods}

Men and women 50 to 80 years of age were recruited from Austin, Texas and the surrounding communities. Every subject had a systolic BP at rest from 140 to $159 \mathrm{~mm} \mathrm{Hg}$ (stage 1 systolic hypertension) or 120 to $139 \mathrm{~mm} \mathrm{Hg}$ (prehypertension) with a diastolic BP of $<99 \mathrm{~mm} \mathrm{Hg} .{ }^{1}$ No subjects had been smoking or taking antihypertensive medications. Subjects were free of overt chronic diseases based on medical history, blood chemistries, physical examination, and at-rest and maximal treadmill exercise electrocardiograms. No subjects had performed regular exercise during the preceding 2 years. They also had no orthopedic complications that would have prohibited them from exercising. The nature, purpose, and risks of the study were explained to each subject before written informed consent was obtained.

After baseline measurements subjects were assigned to swimming exercises or relaxation exercises (attention control). Group assignments were made as randomly as possible, with some regard given to individual preference when a few subjects strongly objected to their group assignment. Elimination of subjects who were not randomized did not affect the overall results. During the course of this investigation subjects in the 2 groups were instructed to maintain their usual lifestyle and dietary habits. This was verified by dietary analyses and maximal oxygen consumption tests.

Subjects in the swimming exercise group participated in a supervised 12-week swimming training program. For the 
Table 1

Selected subject characteristics and blood concentration of humoral factors

\begin{tabular}{|c|c|c|c|c|}
\hline \multirow[t]{2}{*}{ Variable } & \multicolumn{2}{|c|}{ Attention Control } & \multicolumn{2}{|c|}{ Swimming Training } \\
\hline & $\begin{array}{c}\text { Before } \\
(n=19)\end{array}$ & $\begin{array}{c}\text { After } \\
(n=19)\end{array}$ & $\begin{array}{c}\text { Before } \\
(n=24)\end{array}$ & $\begin{array}{c}\text { After } \\
(\mathrm{n}=24)\end{array}$ \\
\hline Men/women & $4 / 15$ & $4 / 15$ & $7 / 17$ & $7 / 17$ \\
\hline Age (years) & $61 \pm 2$ & - & $58 \pm 2$ & - \\
\hline Height $(\mathrm{cm})$ & $165 \pm 2$ & $165 \pm 2$ & $168 \pm 2$ & $167 \pm 2$ \\
\hline Body mass $(\mathrm{kg})$ & $87 \pm 4$ & $86 \pm 4$ & $81 \pm 3$ & $80 \pm 3$ \\
\hline Body mass index $\left(\mathrm{kg} / \mathrm{m}^{2}\right)$ & $32 \pm 1$ & $31 \pm 1$ & $29 \pm 1$ & $28 \pm 1$ \\
\hline Body fat $(\%)$ & $42 \pm 2$ & $43 \pm 2$ & $39 \pm 2$ & $38 \pm 2$ \\
\hline Lean body mass (kg) & $45 \pm 2$ & $44 \pm 2$ & $45 \pm 2$ & $46 \pm 2$ \\
\hline Physical activity score (unit) & $12 \pm 2$ & - & $14 \pm 2$ & - \\
\hline Maximal oxygen consumption (ml/kg/min) & $27 \pm 1$ & $27 \pm 1$ & $28 \pm 1$ & $30 \pm 1$ \\
\hline Total cholesterol (mg/dl) & $211 \pm 10$ & $196 \pm 9$ & $202 \pm 8$ & $196 \pm 9$ \\
\hline Low-density lipoprotein cholesterol (mg/dl) & $137 \pm 10$ & $132 \pm 7$ & $127 \pm 8$ & $120 \pm 10$ \\
\hline High-density lipoprotein cholesterol (mg/dl) & $53 \pm 4$ & $52 \pm 5$ & $57 \pm 4$ & $60 \pm 4$ \\
\hline Triglyceride (mg/dl) & $128 \pm 18$ & $125 \pm 15$ & $120 \pm 12$ & $121 \pm 16$ \\
\hline Glucose $(\mathrm{mg} / \mathrm{dl})$ & $102 \pm 2$ & $97 \pm 2$ & $97 \pm 3$ & $94 \pm 2$ \\
\hline Hemoglobin A1c (\%) & $4.5 \pm 0.1$ & $4.7 \pm 0.1$ & $4.7 \pm 0.1$ & $4.5 \pm 0.1$ \\
\hline Interleukin-6 (pg/ml) & $5.2 \pm 0.9$ & $4.8 \pm 1.1$ & $5.2 \pm 2.0$ & $4.8 \pm 0.8$ \\
\hline Interleukin-7 (pg/ml) & $4.2 \pm 0.7$ & $2.9 \pm 1.0$ & $3.4 \pm 0.8$ & $3.5 \pm 0.6$ \\
\hline Interleukin-10 (pg/ml) & $20.4 \pm 5.5$ & $19.8 \pm 7.1$ & $26.2 \pm 10.1$ & $29.1 \pm 13.3$ \\
\hline Tumor necrosis factor- $\alpha(\mathrm{pg} / \mathrm{ml})$ & $7.5 \pm 0.6$ & $7.7 \pm 0.9$ & $6.2 \pm 0.6$ & $6.4 \pm 0.5$ \\
\hline Total caloric intake (kcal/day) & $1,924 \pm 177$ & $1,855 \pm 152$ & $1,984 \pm 98$ & $1,980 \pm 87$ \\
\hline Protein intake $(\mathrm{g})$ & $75 \pm 6$ & $89 \pm 10$ & $86 \pm 4$ & $81 \pm 7$ \\
\hline Fat intake $(g)$ & $78 \pm 10$ & $80 \pm 12$ & $81 \pm 8$ & $74 \pm 6$ \\
\hline Carbohydrate intake (g) & $203 \pm 19$ & $231 \pm 27$ & $209 \pm 15$ & $207 \pm 13$ \\
\hline Alcohol intake $(\mathrm{g})$ & $5 \pm 1$ & $9 \pm 4$ & $8 \pm 4$ & $10 \pm 4$ \\
\hline
\end{tabular}

Values are means \pm SEMs.

first few weeks subjects were instructed by an instructor and swam 15 to 20 minutes/day, 3 to 4 days/week at a relatively low intensity of exercise ( $\sim 60 \%$ of maximal heart rate). As their overall level of fitness and exercise skill improved, the intensity and duration of exercise increased to 40 to 45 minutes/day, 3 to 4 days/week at a moderate intensity of $70 \%$ to $75 \%$ of maximal heart rate. Target heart rate was adjusted based on the observation that maximal heart rate during swimming is approximately 10 to 13 beats/ min lower than that during running. ${ }^{4,5}$ Each subject was instructed to swim continuously except during the time needed for checking a target heart rate (by Polar heart rate monitor (Polar Electro, Lake Success, New York) secured on a subject's chest).

The attention time control group was necessary to control for the possibility of random changes over time and the "attention" that the swimming training subjects received from their frequent interactions with the investigators, which could affect dependent variables independent of the intervention. ${ }^{6}$ Subjects in the control group visited the laboratory at the same frequency as subjects in the exercise intervention and underwent general progressive relaxation exercises $^{7}$ that included a mixture of progressive relaxation and autogenic relaxation. In addition, gentle static stretching exercises for the entire body were used.

All post-training measurements were performed 24 to 48 hours after the last exercise session to avoid the immediate effects of a single bout of exercise. In addition, measurements before and after intervention periods were obtained at the same time of day for each subject.
Lean body mass and body fat percentage were determined by dual energy x-ray absorptiometry using a Lunar DPX (Lunar, Madison, Wisconsin).

Bilateral brachial and ankle BP and carotid and femoral pulse-wave velocities (PWVs) were measured by an automated vascular testing device (VP-2000, Omron Healthcare, Bannockburn, Illinois) ${ }^{8}$ Carotid and femoral artery pulsewaves were recorded by arterial applanation tonometry. Time delay was measured automatically with the foot-tofoot method and the PWV was subsequently calculated. Augmentation index, an index of arterial wave reflection and arterial stiffness, was obtained using arterial tonometry on the carotid artery.

BP recordings over a 24-hour period of normal daily activity were measured using a noninvasive ambulatory monitor (Spacelabs, Redlands, Washington). The night-time period was defined as the time when the subject went to bed at night until rising the following morning.

Graded exercise testing was undertaken using a metabolic cart during a modified Bruce protocol. After a 5-minute warm-up subjects walked or ran while the treadmill slope was gradually increased by $2 \%$ every 2 minutes until volitional exhaustion.

Stroke volume and cardiac output were measured using a sector transducer connected to an ultrasound machine (Philips iE33, Philips, Bothel, Washington).

Carotid arterial compliance was measured by a combination of ultrasound imaging on the carotid artery and simultaneous applanation tonometry on the contralateral carotid artery as previously described. ${ }^{9}$ Longitudinal images 
Table 2

Casual blood pressure at rest and 24-hour ambulatory blood pressure

\begin{tabular}{|c|c|c|c|c|}
\hline \multirow[t]{2}{*}{ Variable } & \multicolumn{2}{|c|}{ Attention Control } & \multicolumn{2}{|c|}{ Swimming Training } \\
\hline & $\begin{array}{c}\text { Before } \\
(\mathrm{n}=19)\end{array}$ & $\begin{array}{c}\text { After } \\
(\mathrm{n}=19)\end{array}$ & $\begin{array}{c}\text { Before } \\
(\mathrm{n}=24)\end{array}$ & $\begin{array}{c}\text { After } \\
(\mathrm{n}=24)\end{array}$ \\
\hline \multicolumn{5}{|l|}{ Casual blood pressure } \\
\hline Systolic blood pressure $(\mathrm{mm} \mathrm{Hg})$ & $129 \pm 4$ & $129 \pm 4$ & $131 \pm 3$ & $122 \pm 4^{*}$ \\
\hline Mean blood pressure (mm Hg) & $96 \pm 3$ & $96 \pm 3$ & $97 \pm 2$ & $90 \pm 3$ \\
\hline Diastolic blood pressure (mm $\mathrm{Hg})$ & $76 \pm 2$ & $75 \pm 2$ & $76 \pm 2$ & $72 \pm 2$ \\
\hline Pulse pressure $(\mathrm{mm} \mathrm{Hg})$ & $53 \pm 3$ & $54 \pm 1$ & $55 \pm 2$ & $51 \pm 2$ \\
\hline \multicolumn{5}{|l|}{ 24-Hour ambulatory blood pressure } \\
\hline Daytime systolic blood pressure (mm Hg) & $132 \pm 8$ & $129 \pm 5$ & $128 \pm 5$ & $119 \pm 2^{*}$ \\
\hline Daytime mean blood pressure $(\mathrm{mm} \mathrm{Hg})$ & $98 \pm 4$ & $95 \pm 2$ & $95 \pm 3$ & $89 \pm 2$ \\
\hline Daytime diastolic blood pressure $(\mathrm{mm} \mathrm{Hg})$ & $79 \pm 3$ & $80 \pm 2$ & $78 \pm 3$ & $73 \pm 2$ \\
\hline Daytime pulse pressure $(\mathrm{mm} \mathrm{Hg})$ & $49 \pm 6$ & $49 \pm 4$ & $50 \pm 3$ & $46 \pm 2$ \\
\hline Night-time systolic blood pressure $(\mathrm{mm} \mathrm{Hg})$ & $110 \pm 3$ & $108 \pm 4$ & $109 \pm 4$ & $104 \pm 3$ \\
\hline Night-time mean blood pressure $(\mathrm{mm} \mathrm{Hg})$ & $82 \pm 2$ & $78 \pm 4$ & $81 \pm 3$ & $78 \pm 2$ \\
\hline Night-time diastolic blood pressure $(\mathrm{mm} \mathrm{Hg})$ & $65 \pm 2$ & $63 \pm 2$ & $65 \pm 2$ & $62 \pm 2$ \\
\hline Night-time pulse pressure $(\mathrm{mm} \mathrm{Hg})$ & $45 \pm 7$ & $45 \pm 4$ & $45 \pm 3$ & $43 \pm 3$ \\
\hline
\end{tabular}

Values are means \pm SEMs.

$* \mathrm{p}<0.05$ versus before.

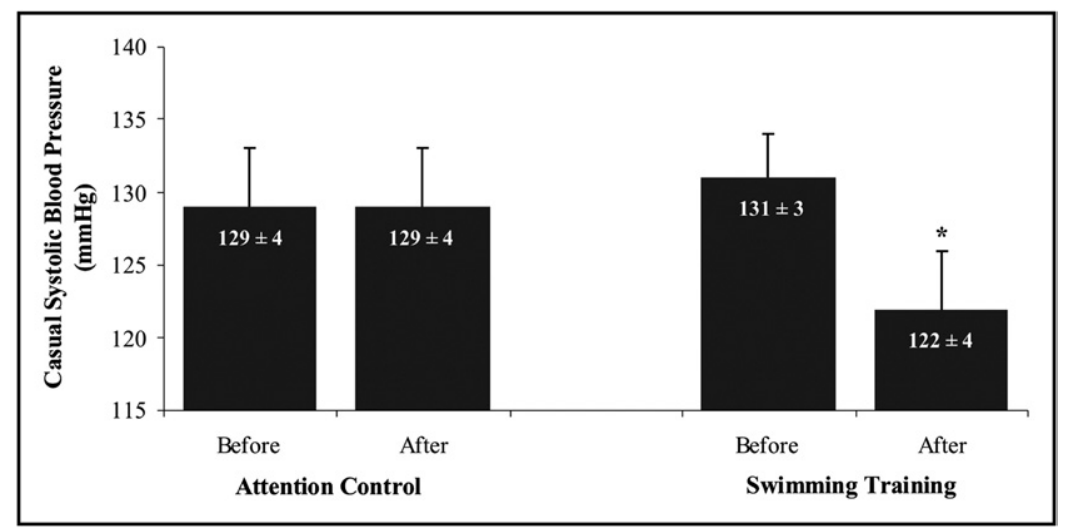

Figure 1. Changes in casual systolic blood pressure in the swimming exercise intervention group $(\mathrm{n}=24)$ and attention control group $(\mathrm{n}=19)$. Values are means \pm SEMs. ${ }^{*} \mathrm{p}<0.05$ versus before.

of the common carotid artery were acquired using an ultrasound machine (Philips iE33) and analyzed using image analysis software (Medical Imaging Applications, Coralville, Iowa). The pressure waveform and amplitude were obtained from the contralateral carotid artery using arterial applanation tonometry (VP-2000, Omron Healthcare) and analyzed by the investigator who was blinded to the group assignment using waveform browsing software (Dataq, Akron, Ohio).

Brachial flow-mediated dilation (FMD) was measured using a standard procedure. ${ }^{10}$ Brachial diameter and blood flow velocity were acquired from a Doppler ultrasound machine equipped with a high-resolution linear array transducer (Philips iE33). After baseline images were obtained the cuff placed on the forearm was inflated to $100 \mathrm{~mm} \mathrm{Hg}$ above an individual subject's systolic BP for 5 minutes. All ultrasound-derived blood flow and diameter data were analyzed by the same investigator who was blinded to the experimental condition using image analysis software.

Cardiovagal baroreflex sensitivity (BRS) was determined using the Valsalva maneuver as previously described. ${ }^{11}$
Subjects were asked to exhale forcibly against a closed airway and maintain an expiratory mouth pressure of 40 $\mathrm{mm} \mathrm{Hg}$ for 10 seconds. The RR interval of the electrocardiogram and beat-by-beat BP (Portapres, Finapres Medical Systems, Amsterdam, The Netherlands) were measured continuously. Data for cardiovagal BRS were recorded and analyzed by waveform browsing software (Windaq 2000, Dataq Instruments, Akron, Ohio) during the phase IV overshoot.

Data were analyzed using analysis of variance with repeated measures. For a significant $F$ value, least significant difference post hoc analysis was used to determine differences. Univariate correlation and regression analyses were used to determine associations between variables of interest.

\section{Results}

Twenty-four adults $>50$ years of age completed the swimming training program and 19 subjects completed the relaxation exercise program. Subjects' adherence to the supervised exercise session was $>99 \%$. Before the 
Table 3

Selected hemodynamic measurements at rest

\begin{tabular}{|c|c|c|c|c|}
\hline Variable & \multicolumn{2}{|c|}{ Attention Control } & \multicolumn{2}{|c|}{ Swimming Training } \\
\hline Carotid systolic pressure (mm $\mathrm{Hg}$ ) & $112 \pm 3$ & $112 \pm 3$ & $109 \pm 4$ & $102 \pm 2 *$ \\
\hline Carotid pulse pressure (mm Hg) & $41 \pm 2$ & $40 \pm 2$ & $41 \pm 2$ & $37 \pm 1$ \\
\hline Carotid artery diameter $(\mathrm{mm})$ & $6.8 \pm 0.2$ & $6.9 \pm 0.2$ & $7.0 \pm 0.2$ & $6.9 \pm 0.2$ \\
\hline Femoral-ankle pulse-wave velocity $(\mathrm{cm} / \mathrm{s})$ & $940 \pm 17$ & $945 \pm 30$ & $914 \pm 20$ & $894 \pm 17$ \\
\hline Carotid augmentation index $(\%)$ & $26 \pm 3$ & $31 \pm 3$ & $30 \pm 2$ & $26 \pm 2$ \\
\hline
\end{tabular}

Values are means \pm SEMs.

$* \mathrm{p}<0.05$ versus before.

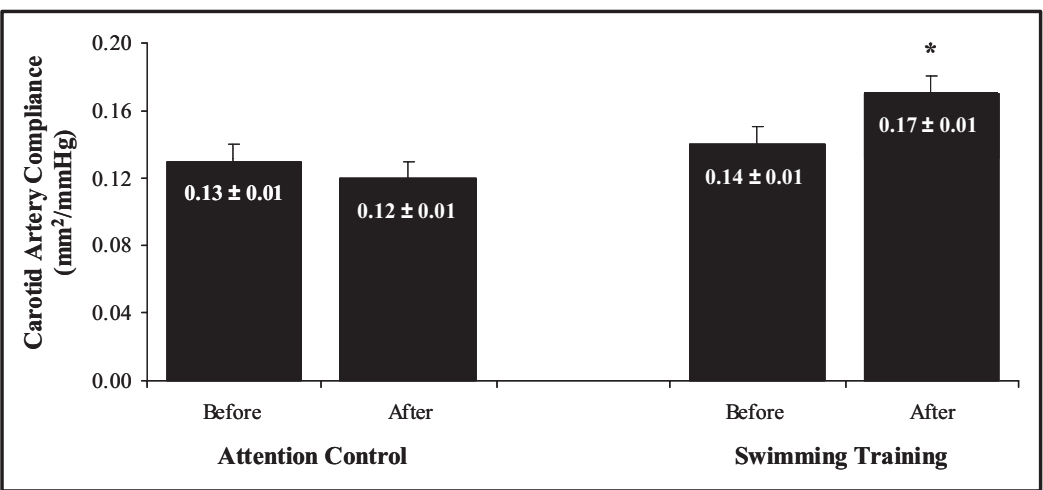

Figure 2. Changes in carotid artery compliance in the swimming exercise intervention group $(\mathrm{n}=24)$ and attention control group $(\mathrm{n}=19)$. Values are means \pm SEMs. ${ }^{*} p<0.05$ versus before.

intervention period (at baseline) there were no significant differences in any physical characteristic variables between the swimming intervention and attention control groups (Table 1).

Subjects in the swimming intervention group were able to gradually and significantly increase their daily swimming distance from the start of intervention. Daily swim distance was significantly increased from $550 \pm 40 \mathrm{~m} /$ day in the first week, to $1,005 \pm 70 \mathrm{~m} /$ day at fourth week, and to $1,417 \pm$ $83 \mathrm{~m} /$ day in the final week. Maximal oxygen consumption during treadmill exercise did not change significantly with swimming training (Table 1). Body mass, adiposity, and plasma concentrations of cholesterol, glucose, or inflammatory cytokines did not change in either group throughout the intervention period.

There were no group differences in casual BP at rest and daytime or in night-time ambulatory BP at baseline (Table 2). Casual systolic BP decreased $(\mathrm{p}<0.05)$ with swimming training (Figure 1). Casual diastolic BP was decreased by $4 \mathrm{~mm} \mathrm{Hg}$ but this change did not reach statistical significance. Daytime systolic BP decreased significantly with the swimming training intervention, whereas night-time BP did not change. There were no significant changes in any casual and ambulatory $\mathrm{BP}$ values in the attention control group.

Carotid systolic BP decreased significantly after swimming training (Table 3). Femoral-ankle PWV, an index of "peripheral" artery stiffness, and augmentation index did not change significantly in either group during the study period. Swimming exercise produced a $21 \%$ increase in carotid artery compliance $(\mathrm{p}<0.05$; Figure 2$)$ and a $\sim 12 \%$ decrease in the â-stiffness index (data not shown). The improvement in carotid artery compliance was not significantly related to changes in BP and other pertinent physiologic variables.

FMD improved significantly after 3 months of swimming exercise training (Figure 3 ). Regular swimming exercise increased cardiovagal BRS significantly (Figure 4). There were no significant physiologic correlates of change in cardiovagal BRS or brachial FMD in response to the swimming exercise intervention.

\section{Discussion}

The major new findings from the study are as follows. The swimming exercise intervention decreased systolic BP in adults $>50$ years of age with increased BP. Decreases in systolic BP were also observed in daytime ambulatory BP and in central BP measurements. Importantly, decreases in $\mathrm{BP}$ were achieved within a relatively short period using a frequency and intensity of exercise that most healthy older adults are able to perform. In addition, hypotensive effects of swimming training were accompanied by significant improvements in arterial compliance, endothelium-dependent 


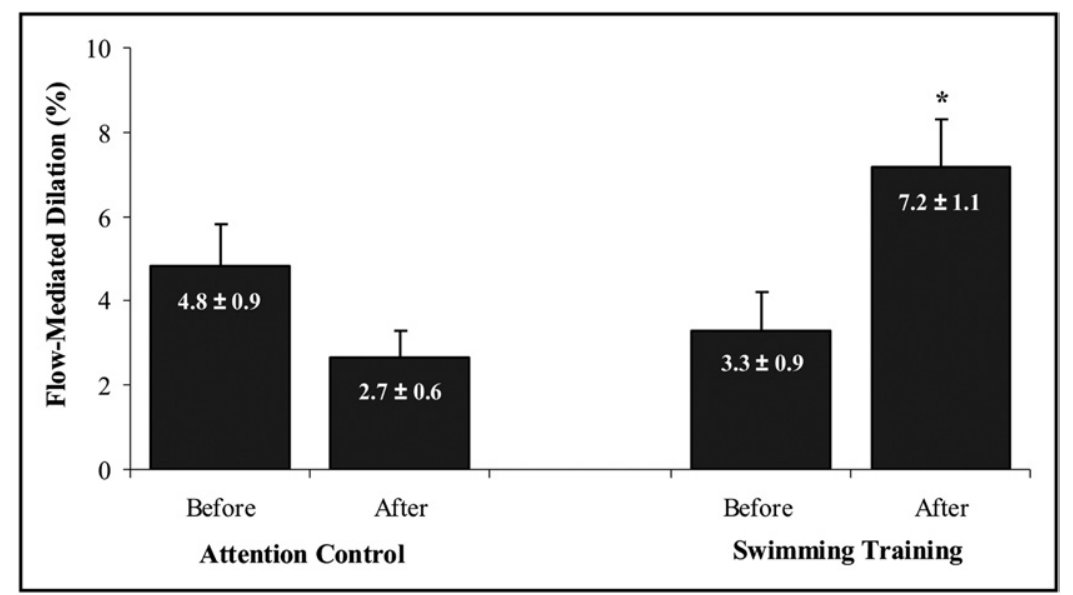

Figure 3. Changes in brachial flow-mediated dilation in the swimming exercise intervention group $(\mathrm{n}=24)$ and attention control group $(\mathrm{n}=19)$. Values are means \pm SEMs. ${ }^{*} \mathrm{p}<0.05$ versus before.

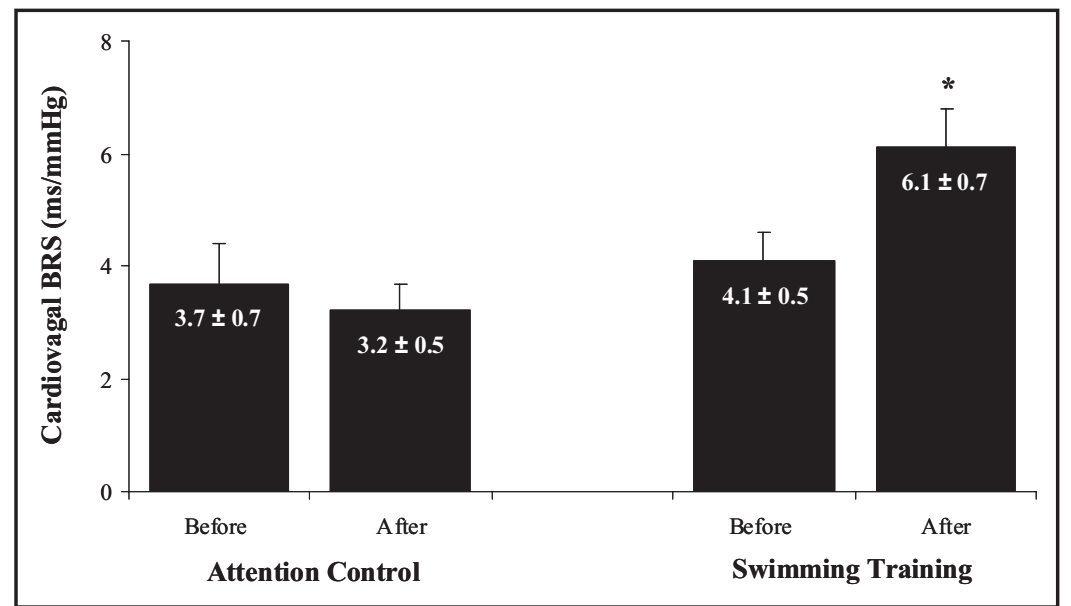

Figure 4. Changes in cardiovagal baroreflex sensitivity $(B R S)$ in the swimming exercise intervention group $(n=24)$ and attention control group $(n=19)$. Values are means \pm SEMs. ${ }^{*} \mathrm{p}<0.05$ versus before.

vasodilation, and cardiovagal BRS, key measurements of vascular functions that are closely associated with the pathogenesis of vascular diseases. To the best of our knowledge this is the first interventional study to demonstrate the multitude of beneficial effects of swimming on key vascular functions.

Current exercise recommendations on swimming and BP are based primarily on results of a small-scale study in which 12 adults with stage 1 or 2 hypertension underwent a 10 -week swimming program and exhibited decreases in systolic and diastolic BPs. ${ }^{4}$ No other data existed on the effect of swimming training on BP in a hypertensive population. We found that a relatively brief period of regular swimming resulted in significant decreases in systolic BP. The BP-lowering effects of swimming exercise manifested in casual, ambulatory, and central BP measurements. These are novel and important findings because decreases in cardiovascular morbidity and mortality by antihypertensive treatments cannot be fully explained by the lowering of traditional brachial (casual) BP measurements. ${ }^{12}$

We previously demonstrated that regular walking exercise attenuates age-associated decreases in large artery compliance and partly restores compliance in previously seden- tary older adults. ${ }^{9,13,14}$ In our recent cross-sectional study central arterial compliance was greater in swimmers than in age-matched sedentary controls and the level of arterial compliance was not different from that of runners. ${ }^{15}$ The present follow-up intervention study allowed us to confirm these cross-sectional observations by demonstrating that regular swimming exercise produced a $21 \%$ increase in arterial compliance and a $12 \%$ decrease in the â-stiffness index after 3 months of regular swimming exercise. It should be noted that changes in arterial compliance were not associated with changes in systolic BP. As such, factors other than arterial compliance may have acted to decrease BP through swimming exercises.

Land-based exercises (e.g., walking) improve endothelialdependent vasodilation in apparently healthy older men ${ }^{16}$ and in patients with metabolic syndrome. ${ }^{17}$ The present study demonstrated for the first time that regular swimming exercise is an effective lifestyle intervention for reversing the loss in endothelial-dependent vasodilation in older sedentary adults. Improved endothelial function, if sustained, should decrease the risk of cardiovascular disease and related thrombotic events in this population. Moreover, this improvement was not associated with changes in body 
mass, adiposity, BP, total cholesterol, or maximal aerobic capacity, suggesting a primary effect of swimming exercise on endothelial function.

Previous intervention studies have demonstrated increases in cardiovagal BRS after land-based exercise training. ${ }^{18,19}$ No information was available on the effects of regular swimming exercise on cardiovagal BRS. We found a $\sim 50 \%$ increase in cardiovagal BRS after swimming exercise training. The relative magnitude of improvement in cardiovagal BRS in the present swimming intervention was similar to a previous land-based (walking) intervention study using similar exercise intensity and duration. ${ }^{18}$ Taken together, these results indicate that swimming exercise can yield a magnitude of beneficial effects on BRS similar to walking exercises.

This study has several limitations. The present study population is limited in size and does not represent a random sample of older adults but rather a convenience sample of healthy adults. As such, our findings cannot be considered representative of the aging population.

In contrast to the public perception that swimming is a "minor" form of exercise, it is 1 of the most popular and most practiced forms of physical activity. In the United States and most industrialized countries, swimming is the second most popular dynamic exercise method in older adults. ${ }^{20-22}$ An estimated 8.6 million swimming pools are in public or residential use in the United States. Despite the nationwide and worldwide popularity of swimming, the efficacy of swimming to modify vascular risk factors is largely unknown. The present study was the first to systematically address this fundamental question that directly impacts exercise prescription for older adults with increased BP. Results of the present study support the idea that swimming exercise elicits BP-lowering effects and improvements in vascular function in previously sedentary older adults. This is a clinically important finding because swimming can be a highly suitable exercise alternative to or in conjunction with land-based exercises for prevention and treatment of risk factors for cardiovascular disease.

1. Chobanian AV, Bakris GL, Black HR, Cushman WC, Green LA, Izzo JL, Jr., Jones DW, Materson BJ, Oparil S, Wright JT Jr, Roccella EJ; National Heart, Lung, and Blood Institute Joint National Committee on Prevention, Detection, Evaluation, and Treatment of High Blood Pressure, National High Blood Pressure Education Program Coordinating Committee. The Seventh Report of the Joint National Committee on Prevention, Detection, Evaluation, and Treatment of High Blood Pressure: the JNC 7 report. JAMA 2003;289:2560-2572.

2. Fagard RH. Exercise characteristics and the blood pressure response to dynamic physical training. Med Sci Sports Exerc 2001;33(suppl): S484-S492.

3. Tanaka H. Swimming exercise: impact of aquatic exercise on cardiovascular health. Sports Med 2009;39:377-387.

4. Tanaka H, Bassett DR, Howley ET, Thompson DL, Ashraf M, Rawson FL. Swimming training lowers the resting blood pressure in individuals with hypertension. J Hypertens 1997;15:651-657.
5. DiCarlo LJ, Sparling PB, Millard-Stafford ML, Rupp JC. Peak heart rates during maximal running and swimming: implications for exercise prescription. Int J Sports Med 1991;12:309-312.

6. Martin JE, Dubbert PM, Cushman WC. Controlled trial of aerobic exercise in hypertension. Circulation 1990;81:1560-1567.

7. van Montfrans GA, Karemaker JM, Wieling W, Dunning AJ. Relaxation therapy and continuous ambulatory blood pressure in mild hypertension: a controlled study. BMJ 1990;300:1368-1372.

8. Cortez-Cooper MY, Supak JA, Tanaka H. A new device for automatic measurements of arterial stiffness and ankle-brachial index. Am J Cardiol 2003;91:1519-1522.

9. Tanaka H, Dinenno FA, Monahan KD, Clevenger CM, DeSouza CA, Seals DR. Aging, habitual exercise, and dynamic arterial compliance. Circulation 2000;102:1270-1275.

10. Corretti MC, Anderson TJ, Benjamin EJ, Celermajer D, Charbonneau F, Creager MA, Deanfield J, Drexler H, Gerhard-Herman M, Herrington D, Vallance P, Vita J, Vogel R; International Brachial Artery Reactivity Task Force. Guidelines for the ultrasound assessment of endothelial-dependent flow-mediated vasodilation of the brachial artery: a report of the International Brachial Artery Reactivity Task Force. J Am Coll Cardiol 2002;39:257-265.

11. Monahan KD, Tanaka H, Dinenno FA, Seals DR. Central arterial compliance is associated with age- and habitual exercise-related differences in cardiovagal baroreflex sensitivity. Circulation 2001;104: $1627-1632$.

12. Williams B, Lacy PS, Thom SM, Cruickshank K, Stanton A, Collier D, Hughes AD, Thurston H, O'Rourke M; CAFE Investigators, AngloScandinavian Cardiac Outcomes Trial Investigators, CAFE Steering Committee and Writing Committee. Differential impact of blood pressure-lowering drugs on central aortic pressure and clinical outcomes: principal results of the Conduit Artery Function Evaluation (CAFE) study. Circulation 2006;113:1213-1225.

13. Moreau KL, Donato AJ, Seals DR, DeSouza CA, Tanaka H. Regular exercise, hormone replacement therapy and the age-related decline in carotid arterial compliance in healthy women. Cardiovasc Res 2003; 57:861-868.

14. Tanaka H, DeSouza CA, Seals DR. Absence of age-related increase in central arterial stiffness in physically active women. Arterioscler Thromb Vasc Biol 1998;18:127-132.

15. Nualnim N, Barnes JN, Tarumi T, Renzi CP, Tanaka H. Comparison of central artery elasticity in swimmers, runners, and the sedentary. Am J Cardiol 2011;107:783-787.

16. DeSouza CA, Shapiro LF, Clevenger CM, Dinenno FA, Monahan KD, Tanaka H, Seals DR. Regular aerobic exercise prevents and restores age-related declines in endothelium-dependent vasodilation in healthy men. Circulation 2000;102:1351-1357.

17. Lavrencic A, Salobir BG, Keber I. Physical training improves flowmediated dilation in patients with the polymetabolic syndrome. Arterioscler Thromb Vasc Biol 2000;20:551-555.

18. Monahan KD, Dinenno FA, Tanaka H, Clevenger CM, DeSouza CA, Seals DR. Regular aerobic exercise modulates age-associated declines in cardiovagal baroreflex sensitivity in healthy men. J Physiol 2000; 529:263-271.

19. Spina RJ, Bourey RE, Ogawa T, Ehsani AA. Effects of exercise training on alpha-adrenergic mediated pressor responses and baroreflex function in older subjects. J Gerontol 1994;49: B277-B281.

20. Vaz de Almeida MD, Graça P, Afonso C, D'Amicis A, Lappalainen R, Damkjaer S. Physical activity levels and body weight in a nationally representative sample in the European Union. Public Health Nutr 1999;2:105-113.

21. Afonso C, Graça P, Kearney JM, Gibney MJ, de Almeida MD. Physical activity in European seniors: attitudes, beliefs and levels. $J$ Nutr Health Aging 2001;5:226-229.

22. Kolt GS, Driver RP, Giles LC. Why older Australians participate in exercise and sport. J Aging Phys Act 2004;12:185-198. 